\title{
Customized SmartPeg for measurement of resonance frequency of mini dental implants
}

Jagjit Singh Dhaliwal ${ }^{1,4}$, Rubens F. Albuquerque $\mathrm{Jr}^{2}$, Ali Fakhry ${ }^{1}$, Sukhbir Kaur ${ }^{3}$ and Jocelyne S. Feine ${ }^{1 *}$

\begin{abstract}
Background: One-piece narrow diameter implants (NDIs) have been recommended as "Single-tooth replacements in the anterior zones, single posterior, multiple-unit fixed dental prosthesis (FDP), edentulous jaws to be rehabilitated with FDP, and edentulous jaws rehabilitation with overdentures in situations with reduced mesiodistal space or reduced ridge width." (ITI consensus 2013). Since NDls can be immediately loaded, it is important to be able to carry out stability testing. We developed and validated a customized SmartPeg for this type of implant to measure the Implant Stability Quotient (ISQ). The ISQ of mini dental implants (MDIs) was measured and compared with the stability of standard and in a rabbit model.
\end{abstract}

Objective: The aim of the study is to test the feasibility of a customized SmartPeg for resonance frequency measurement of single-piece mini dental implants and to compare primary stability of a standard and the mini dental implant $\left(3 \mathrm{M}^{\mathrm{TM}} \mathrm{ESPE} \mathrm{E}^{\mathrm{TM}} \mathrm{MDI}\right)$ in a rabbit model after 6 weeks of healing.

Methods: Eight New Zealand white rabbits were used for the study. The protocol was approved by the McGill

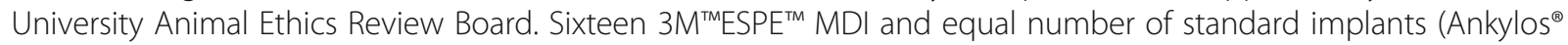
Friadent, Dentsply) were inserted into the tibia/femur of the rabbits and compared. Each rabbit randomly received two $3 \mathrm{M}^{\mathrm{TM}}$ ESPE ${ }^{\mathrm{TM}} \mathrm{MDI}$ and two Ankylos ${ }^{\circledast}$ implants in each leg. ISQ values were measured with the help of an Osstell ISQ device using custom-made SmartPegs for the MDls and implant-specific SmartPegs ${ }^{\text {TM }}$ (Osstell) for the Ankylos ${ }^{\oplus}$. Measurements were obtained both immediately following implant placement surgery and after a 6-week healing period. Each reading was taken thrice and their average compared using Wilcoxon matched pairs signed-rank tests.

Results: The median ISQ and interquartile range (IQR) values were 53.3 (8.3) at insertion and 60.5 (5.5) at 6 weeks for the $3 \mathrm{M}^{\mathrm{TM}} \mathrm{ESPE} \mathrm{E}^{\mathrm{TM} M D I}$ and, respectively, 58.5 (4.75) and 65.5 (9.3) for the Ankylos ${ }^{\circledast}$ implant. These values also indicate that both types of implants achieved primary and secondary stability, and this is supported by histological data. ISQ values of both $3 \mathrm{M}^{\mathrm{TM}} \mathrm{ESPE} \mathrm{E}^{\mathrm{TM}} \mathrm{MDI}$ and $\mathrm{Ankylos}^{\circledR}$ increased significantly from the time of insertion to 6 weeks post-insertion $(p<0.05)$.

Conclusions: The new custom-made SmartPeg is suitable for measuring the Implant Stability Quotient of $3 M^{\mathrm{TM}} \mathrm{ESPE}^{\mathrm{TM}} \mathrm{MDIs}$. The primary stability of $3 \mathrm{M}^{\mathrm{TM}} \mathrm{ESPE}^{\mathrm{TM} M D I s}$ is similar to the primary stability attained by standard implants in the rabbit tibia.

\footnotetext{
* Correspondence: jocelyne.feine@mcgill.ca

${ }^{1}$ Faculty of Dentistry, McGill University, 2001 McGill College Avenue, Suite

500, Montreal, Quebec H3A 1G1, Canada

Full list of author information is available at the end of the article
} 


\section{Background}

Osseointegration refers to the phenomenon for close apposition of the bone to the surface of an implant with no interposing tissue that can be clinically demonstrated by absence of mobility $[1,2]$. Obtaining primary stability seems to be a precondition for a successful osseointegration [3]. Dental implants have a success rate of over $90 \%$ and are available in various sizes with different surfaces $[4,5]$. The diameter of dental implants usually ranges from $3 \mathrm{~mm}$ (narrow diameter) to $7 \mathrm{~mm}$ (wide diameter), with the majority falling in the "standard diameter" range of 3.7 to $4.0 \mathrm{~mm}$.

Single-piece mini dental implants (MDIs) or narrow diameter implants (NDIs) are being widely used for stabilizing complete dentures [6], orthodontic anchorage $[7,8]$, single-tooth replacements, and fixing surgical guides for definitive implant placement, and as transitional implants for support of interim removable prosthesis during the healing phase of final fixtures [9-11].

Due to the MDIs' narrower diameter $(1.8-2.4 \mathrm{~mm})$ as compared with regular implants, the width of the bone required for their placement is smaller, making the surgery minimally invasive as compared with the surgery for conventional implant insertion [12]. In addition, transmucosal placement is performed using a single pilot drill, reducing the need for sutures and long recovery periods [13]. Mini dental implants can also be immediately loaded and are cost-effective, which makes them an advantageous alternative for mandibular implant overdentures [13, 14]. The success of these implants will depend, however, on their capacity to outstand functional loadings.

Osseointegrated implants are clinically characterized by the absence of mobility, which can be assessed by measuring the primary and secondary implant stability $[15,16]$. Some authors have suggested that primary stability is a critical factor in predicting whether an implant will be successful or not, and it is considered of highest importance in the long-term success of dental implants $[17,18]$. It has also been reported that micro movements can be detected at an early stage by measuring the primary implant stability and that they are unfavorable to the osseointegration of dental implants [19-21].

Mechanical testing methods like reverse torque, or "pullout test," have been used to study and measure the mechanical interface between implant and bone in various ways [22, 23]. The Branemark group has evaluated the mechanical properties of osseointegrated implants using torsion and pullout tests and lateral loading tests [24, 25]. Presence or absence of mobility and the bone level around the implant can be estimated by non-invasive methods based on resonance frequency analysis (RFA) such as those used by Periotest and Osstell ${ }^{\text {ti }}$ devices [26-30].

Resonance frequency analysis has been used to document changes in the bone healing along the implant- bone interface by measuring the stiffness of implant in the bone tissue [31-34]. It has also been used to determine whether implants are ready for the final restoration [35] or ready to be loaded [33] and to identify the implants at "risk" [36]. The first studies using RFA were published in 1996 [37]. In 1997, Meredith et al. suggested a non-invasive method for determining the resonance frequency associated with dental implants by connecting an adapter/transducer onto the abutment in an animal study [38]. The experimented RFA system, base on magnetic pulses, has been commercially produced as Osstell since the year 2000 [19] (Osstell AB, Göteborg, Sweden). Osstell was later followed by Osstell Mentor $^{\mathrm{Tm}}$ and Osstell ISQ ${ }^{\mathrm{Tm}}$. It calculates the Implant Stability Quotient (ISQ) converting kilohertz units to ISQ on a scale of $1-100$, where 100 signifies the highest implant stability. Increases in ISQ measurements indicate improved bone stiffness and healing around the implant and better implant stability. The Osstell ISQ works by introducing a controlled vibration to the implant by means of a sensor and a rod (SmartPeg) connected to the implant and measuring its frequency. These SmartPegs are usually fabricated for standard diameter implants. The osseointegration potential of single-piece mini dental implants $\left(3 \mathrm{M}^{\mathrm{TM}} \mathrm{ESPE} \mathrm{E}^{\mathrm{m}} \mathrm{MDIs}\right)$ has never been assessed by RFA. The immediate post-surgical ISQ assessment of MDIs is particularly relevant due to their smaller size and surface area in comparison to standard implants.

There are no published studies on the ISQ measurement of mini dental implants, as SmartPegs for these implants are not available till date. Since these are onepiece implants and do not have an internal thread for the SmartPeg's attachment, a custom-made SmartPeg needs to be fabricated for ISQ measurement. Therefore, we developed and tested a customized SmartPeg for $3 \mathrm{M}^{\mathrm{Tm}} \mathrm{ESPE}^{\mathrm{Tm}} \mathrm{MDIs}$ to measure the ISQ.

\section{Objective}

The aim of the study is to test the feasibility of a customized SmartPeg for ISQ measurement of single-piece mini dental implants and to compare the primary stability of a standard and the mini dental implant (3M $\left.\mathrm{M}^{\mathrm{rm}} E S P E^{\mathrm{mm}} \mathrm{MDI}\right)$ in a rabbit model after 6 weeks of healing.

\section{Methods}

\section{Development of a customized SmartPeg}

Single use Osstell SmartPegs for standard implants are made from a soft metal with a zinc-coated magnet mounted on top of it and attached to the implants or abutments' internal threads. As the company does not provide SmartPegs for one-piece implants, we developed a customized SmartPeg for mini dental implants $\left(3 \mathrm{M}^{\mathrm{Tm}} \mathrm{ESPE}^{\mathrm{mm}} \mathrm{MDIs}\right)$, which do not have internal threads 
(Fig. 1). After confirming that the standard SmartPegs ${ }^{\mathrm{m}}$ are fabricated in aluminum, we customized a prototype in the same metal with a square-shaped assembly, which could be tightened with a small screw over the spherical top end of the MDIs. Our SmartPeg prototype was tested for reproducibility verifying the ISQ values on an MDI inserted into a wooden plank made of balsa wood. RFA measurements were taken 50 times, and a standard error of mean of all measurements was calculated.

\section{Animal model and sample size}

Eight clinically healthy New Zealand white rabbits weighing $>3.5 \mathrm{~kg}$ used for the study were housed in the Central Animal House facility. The head of the tibia/ femur of the animals were chosen for the implantation of samples because they have been widely used as an animal model, and so, our results could be promptly compared [39-46]. The sample size of this study has been calculated based on the results of a similar study [36]. It was expected that $88 \%$ statistical power would be achieved by using sixteen $3 \mathrm{M}^{\mathrm{Tm}} E S P E^{\mathrm{rm}}$ MDIs (experimental) and equal number of regular implants Ankylos', Dentsply Friadent $\mathrm{GmbH}$ (control). Each animal received two implants on each of the hind limbs, i.e., the right and left tibia/femur heads, randomly. Therefore, each animal had a total of four implants, i.e., two experimental and two regular implants, randomly located.

\section{Surgical procedures}

The procedures were approved by the institutional animals' ethics review board of McGill University, Montreal, Canada. Adequate measures were taken into consideration

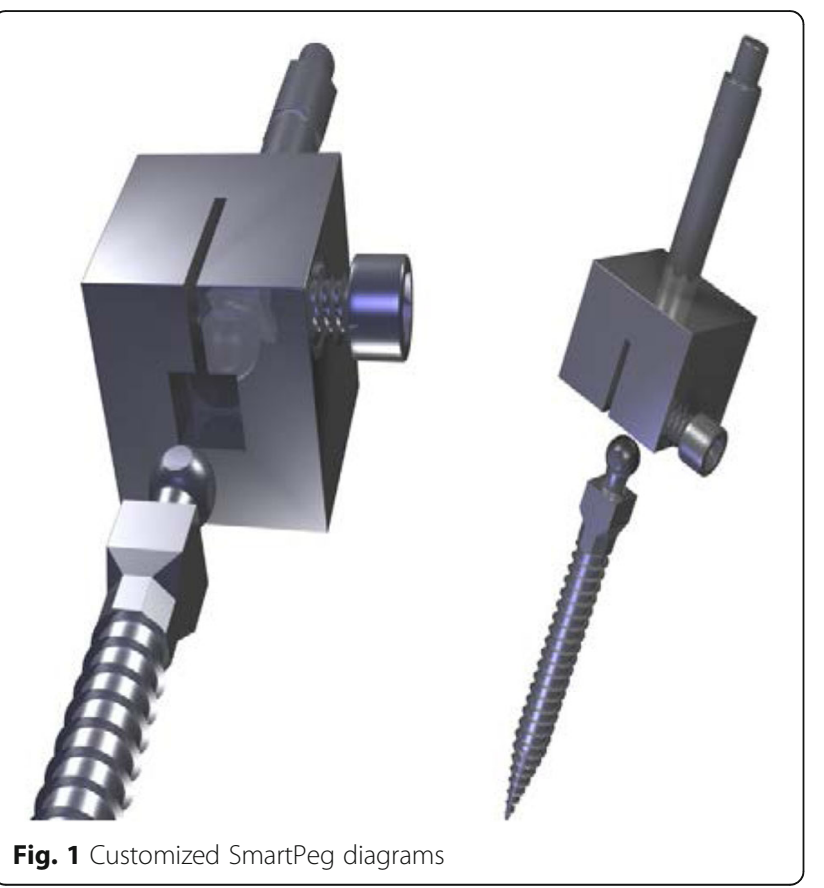

to minimize pain and distress in the animal during the procedure. Animals were anesthetized by intravenous injections of a ketamine hydrochloride-xylazine mixture at $35-50$ and $1-3 \mathrm{mg} / \mathrm{kg}$, respectively, according to the method described by Green et al. [47]. Acepromazine was injected subcutaneously at the dosage of $1 \mathrm{mg} / \mathrm{kg}$. Further injections of the mixture were given to maintain anesthesia, if necessary. All surgical procedures were performed in accordance with McGill's standardized operating protocol (SOP).

For the MDIs, a small longitudinal skin incision was made just distal to the tibia/femur joint. The tibia/femur head was exposed subperiosteally, and an osteotomy was performed with the pilot drill under copious irrigation with saline solution, transposing the cortical bone to the depth of $0.5 \mathrm{~mm}$. The implants were aseptically transferred to the bone site and manually rotated clockwise while exerting downwards pressure to start the selftapping process. When bony resistance was encountered, the winged thumb wrench was used for driving the implant deeper into the bone, if necessary.

Ankylos ${ }^{\circ}$ implants were inserted in the other tibia/ femur head of the animals according to the manufacturer's protocol as follows: After mobilizing the subperiosteal flap and using a 3-mm center punch to register a guiding point for the osteotomy, a twist drill, depth drill series and a conical reamer were used sequentially to complete the osteotomy and to develop a conical shape for accomodation of the implant's body. A counterclockwise rotation was used to compress the bone in case of soft bone. The tap or thread cutter was used to create the threads in dense bones. Following, the implant assembly was aseptically transferred to the osteotomy site, and the implant placement was started manually and finalized using a hand ratchet. If excessive force was experienced, the osteotomy was irrigated, and the depth was checked by retapping.

\section{Resonance frequency assessment}

Resonance frequency assessment was performed thrice, just after the insertion of the implants, using the Osstell ISQ $^{\text {mi }}$ device. In brief, customized SmartPegs were stabilized onto the head of the $3 \mathrm{M}^{\mathrm{m}} \mathrm{ESPE} \mathrm{E}^{\mathrm{mm}}$ MDIs and Osstell company's specific SmartPeg $^{\text {tw }}$ devices were screwed into Ankylos $^{\circ}$ implants, taking care to ensure that no significant torquing force was applied to the implants, and the RFA was carried out. These procedures were repeated for post-euthanasia RFA.

\section{Post-surgical treatment and euthanasia}

The rabbits were given a dose of cephalexin $12 \mathrm{mg} / \mathrm{kg}$ $0.5 \mathrm{~mL}$ IV once intraoperatively and a postoperative analgesic, i.e., carprofen $2-4 \mathrm{mg} / \mathrm{kg}$ SC every $8 \mathrm{~h}$ for 3 days, according to McGill's SOP. The animals had a free 
access to water and food, and routine daily care followed as per McGill's SOP\#524.01. The sutures were removed after 7-10 days, and the animals were euthanized at 6 weeks postoperatively. It has been shown by various authors that this period is adequate to develop a "rigid osseous interface" in rabbits [30]. An overdose of pentobarbital sodium $1 \mathrm{~mL} / \mathrm{kg}$ intravenously was used for this purpose [48].

\section{Statistical analyses}

ISQ values were averaged and compared between implant types and times using Wilcoxon's matched pairs signed-rank tests at a significance level of $p<0.05$. Statistical analysis was performed with the help of SPSS statistical software version 17 .

\section{Results}

The ISQ values obtained while calibrating the customized SmartPeg were similar to in vivo results. Median ISQ values at insertion and at 6 postoperative weeks were 53.3 (IQR 8.3) and 60.5 (5.5) for the $3 \mathrm{M}^{\mathrm{rm}} \mathrm{ESPE}^{\mathrm{rm}} \mathrm{M}$ DIs, and 58.5 (4.75) and 65.5 (9.3) for the Ankylos implants, respectively, with no statistical difference (Figs. 2 and 3). The ISQ values of both $3 \mathrm{M}^{\mathrm{m}} E S P E^{\mathrm{mm}} \mathrm{MDI}$ and Ankylos $^{\circ}$ (Figs. 2 and 3) increased significantly from the time of insertion to 6-week post-insertion $(p<0.05)$.

\section{Discussion}

It is important to measure the Implant Stability Quotient (ISQ) of single-piece mini dental implants as they are becoming increasingly popular, with the concomitant increase in publications demonstrating their high survival and success rates. Although the clinical use of Osstell devices is also increasing, there is lack of studies on its use with single-piece implants, which do not have internal threads. Implant Stability Quotient (ISQ) is an objective and standardized method for measuring implant stability clinically ranging from 55 to 80, with higher values usually observed in the mandible [49]. The ISQ scale has a non-linear correlation to micro mobility. With more than 700 scientific references, we now know that high stability means $>70$ ISQ, between 60 and 69 is medium stability, and $<60$ ISQ is considered as low stability.

The rabbit tibias have been used to determine longitudinal changes in the resonance frequency and measured for over 168 days from the time of implant insertion, and it was observed that resonance frequency values increased over time [38].

However, the relationship between the bone density and ISQ is not significant [50]. Therefore, higher ISQ values are a sign of bone anchorage of implants, but the relationship of resonance frequency analysis with bone structure is unclear [51-53]. ISQ values decline in the first 2 weeks after implant insertion, and these changes may be associated with early bone healing and marginal alveolar bone resorption. Bone remodeling reduces primary bone contact. In the early stage after implant placement, the formation of bony callus and increasing lamellar bone in the cortical bone causes major changes in bone density. Therefore, in the healing process, primary bone contact decreases and secondary bone contact increases [53, 32]. Degidi et al. [54] reported that there may also be a discrepancy as the histological analyses is a two-dimensional picture of the threedimensional bone-implant contact.

If the initial ISQ value is high, a small drop in stability normally levels out with time. A big drop in stability or decrease should be taken as a warning sign. Lower values are expected to be higher after the healing period.

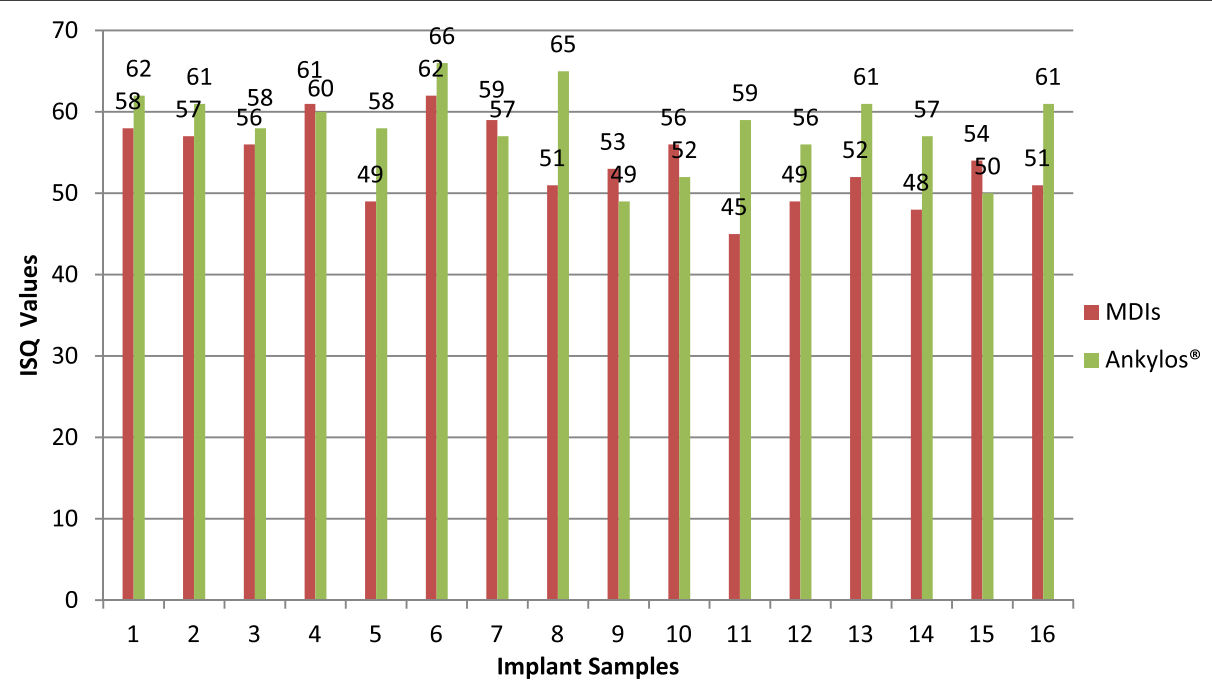

Fig. 2 ISQ values of MDIs and Ankylos ${ }^{\circledast}$ immediately upon insertion 


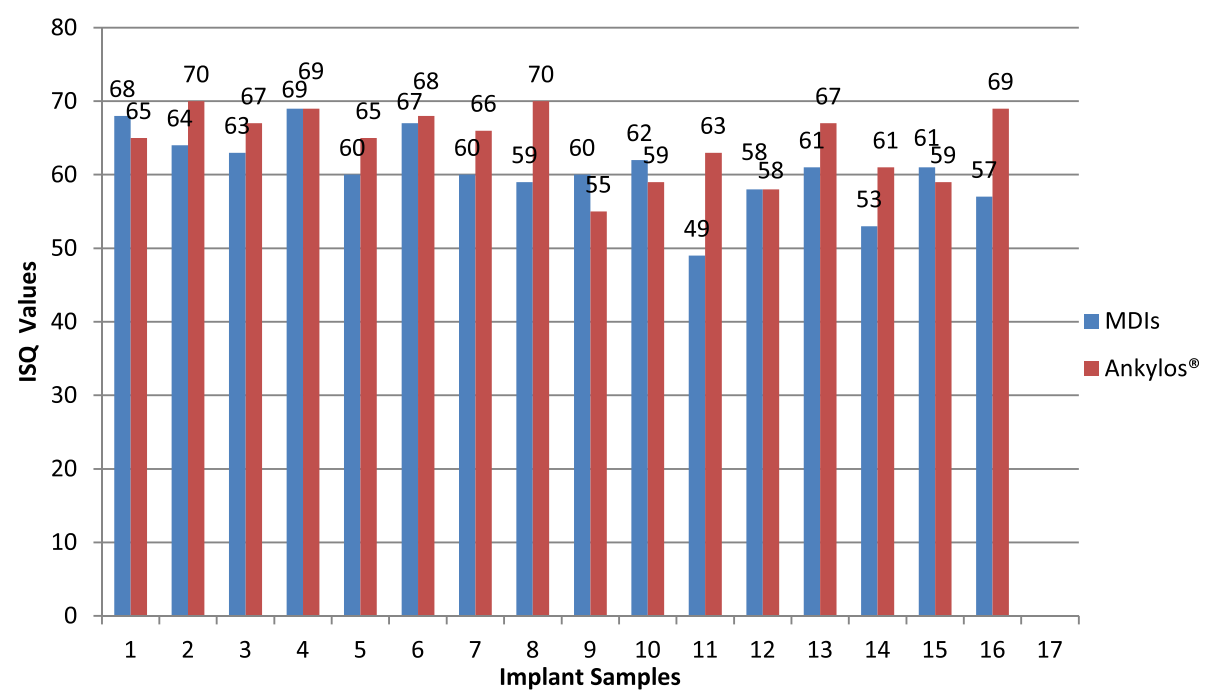

Fig. 3 ISQ values of MDIs and Ankylos ${ }^{\circledast}$ after euthanasia

The opposite could be a sign of an unsuccessful implant, and actions should be taken accordingly.

Studies have shown that the resonance frequency value is greatly associated with the quantity of bone-implant contact $[31,38]$. There is a positive correlation between resonance frequency analysis and histomorphometric measurements [37]. In our histological study previously reported, similar findings were demonstrated [55].

Our results indicate that both types of implants achieved primary and secondary stability.

Several measurements may be more dependable than single measures; therefore, it may be important to measure resonance frequency multiple times and average the values in order to obtain the most reliable assessment. While reliability of resonance frequency analysis has not been established in the past for these mini dental implants used for overdentures, studies have shown similar or lower levels of reliability for regular dental implants [56].

In general, there was an increase in the ISQ values in both groups, which may be related to enhancement of rigidity between the implants and neighboring tissues and largely with the changes at the bone-implant interface. It has been demonstrated that there is a development of woven bone surrounding the implants 1 week following placement in the rabbit tibia. This scantily organized bone is resorbed by osteoclasts and slowly remodeled into the lamellar bone and gets more compacted around the implant surface and remodeled to become a mature bone over a period of 42 days $[38,57]$. There seems to be minimal changes in the resonance frequency after this period. Our results are in concurrence with the study by Meredith et al. [38].

As there are no studies that provide data based on resonance frequency measurements for single-piece MDIs, the exact RFA threshold values for MDIs may have to be identified with more studies conducted in vivo.

The resonance frequency assessment with a customized SmartPeg would be a useful tool to provide clinically useful information about the condition of the boneimplant interface of $3 \mathrm{M}^{\mathrm{Tn}}$ ESPE ${ }^{\mathrm{mm}} \mathrm{MDIs}$. Frequently, implant failures are associated with biomechanical reasons; implant stability assessment can reduce this to a great extent. The higher the RFA value, the higher the success in implant treatment and the lower the risk for failure in the future. On the other hand, lower RFA values may indicate greater risk for implant complications. The MDIs are usually immediately loaded. Resonance frequency measurement technique is also of value in evaluating the immediate loading implants [58]. The results of the present study are encouraging and show that it is possible to measure ISQ for these single-piece MDIs. This study is the first of its kind and similar type of studies should be conducted among humans, to make the results more meaningful and generalizable.

\section{Conclusions}

The results of this animal study indicate that ISQ measurement of these single-piece MDIs is possible with the help of a custom-made SmartPeg and that $3 \mathrm{M}^{\mathrm{m}} \mathrm{ESPE}{ }^{\mathrm{mm}} \mathrm{M}-$ DIs attain primary and secondary stability at the same levels as standard implants in the rabbit tibia.

\section{Authors' contributions}

JSD carried out the experiments and drafted the manuscript, RA conceived the study and helped in revising the manuscript, AF contributed to the designing the SmartPeg, SK helped in the data analysis, JSF participated in this study's design and overall coordination. All authors read and approved the final manuscript. 


\section{Competing interests}

Jagjit Singh Dhaliwal, Rubens F. Albuquerque Jr, Ali Fakhry, Sukhbir Kaur, and Jocelyne $\mathrm{S}$. Feine declare that they have no competing interests.

\section{Ethics approval}

IRB approval, Animal Use Protocol \# 2012-7221, was provided by Suzanne Smith, Director of the Animal Compliance, McGill University, Montreal, Canada.

\section{Author details}

${ }^{1}$ Faculty of Dentistry, McGill University, 2001 McGill College Avenue, Suite 500, Montreal, Quebec H3A 1G1, Canada. ${ }^{2}$ Faculty of Dentistry of Ribeirão Preto, University of São Paulo, Ribeirão Preto, SP, Brazil. ${ }^{3}$ Department of Zoology, Panjab University, Chandigarh, India. ${ }^{4}$ PAPRSB Institute of Health Sciences, Universiti Brunei Darussalam, Brunei Darussalam.

\section{Received: 9 November 2016 Accepted: 13 January 2017} Published online: 01 February 2017

\section{References}

1. Branemark PI, Adell R, Breine U, Hansson BO, Lindstrom J, Ohlsson A. Intraosseous anchorage of dental prostheses. I. Experimental studies. Scand J Plast Reconstr Surg. 1969;3(2):81-100. Epub 1969/01/01

2. Meredith N. Assessment of implant stability as a prognostic determinant. Int J Prosthodont. 1998;11(5):491-501. Epub 1999/01/29.

3. Lioubavina-Hack N, Lang NP, Karring T. Significance of primary stability for osseointegration of dental implants. Clin Oral Implants Res. 2006;17(3):24450. Epub 2006/05/05

4. Albrektsson T, Dahl E, Enbom L, Engevall S, Engquist B, Eriksson AR, et al. Osseointegrated oral implants. A Swedish multicenter study of 8139 consecutively inserted nobelpharma implants. J Periodontol. 1988;59(5):28796. Epub 1988/05/01.

5. Bornstein MM, Valderrama $P$, Jones $A A$, Wilson $T G$, Seibl R, Cochran DL. Bone apposition around two different sandblasted and acid-etched titanium implant surfaces: a histomorphometric study in canine mandibles. Clin Oral Implants Res. 2008;19(3):233-41. Epub 2008/01/08.

6. Bulard RA, Vance JB. Multi-clinic evaluation using mini-dental implants for long-term denture stabilization: a preliminary biometric evaluation. Compend Contin Educ Dent. 2005;26(12):892-7. Epub 2006/01/05.

7. Diedrich P, Fritz U, Kinzinger G, Angelakis J. Movement of periodontally affected teeth after guided tissue regeneration (GTR) — an experimental pilot study in animals. J Orofac Orthop. 2003;64(3):214-27. Epub 2003/07/02.

8. Buchter A, Kleinheinz J, Wiesmann HP, Jayaranan M, Joos U, Meyer U. Interface reaction at dental implants inserted in condensed bone. Clin Oral Implants Res. 2005;16(5):509-17. Epub 2005/09/17.

9. Kwon KR, Sachdeo A, Weber HP. Achieving immediate function with provisional prostheses after implant placement: a clinical report. J Prosthet Dent. 2005:93(6):514-7. Epub 2005/06/09.

10. Kokubo Y, Ohkubo C. Occlusion recording device for dental implantsupported restorations. J Prosthet Dent. 2006;95(3):262-3. Epub 2006/03/18.

11. Ohkubo C, Kobayashi M, Suzuki Y, Sato J, Hosoi T, Kurtz KS. Evaluation of transitional implant stabilized overdentures: a case series report. J Oral Rehabil. 2006:33(6):416-22. Epub 2006/05/05.

12. Campelo LD, Camara JR. Flapless implant surgery: a 10-year clinical retrospective analysis. Int J Oral Maxillofac Implants. 2002;17(2):271-6. Epub 2002/04/18.

13. Shatkin TE, Oppenheimer BD, Oppenheimer AJ. Mini dental implants for long-term fixed and removable prosthetics: a retrospective analysis of 2514 implants placed over a five-year period. Compend Contin Educ Dent. 2007; 28(2):92-9. quiz 100-1. Epub 2007/02/27.

14. Griffitts TM, Collins CP, Collins PC. Mini dental implants: an adjunct for retention, stability, and comfort for the edentulous patient. Oral Surg Oral Med Oral Pathol Oral Radiol Endod. 2005;100(5):e81-4. Epub 2005/10/26.

15. Albrektsson T, Sennerby L. State of the art in oral implants. J Clin Periodontol. 1991;18(6):474-81. Epub 1991/07/01.

16. Atsumi M, Park SH, Wang HL. Methods used to assess implant stability: current status. Int J Oral Maxillofac Implants. 2007;22(5):743-54. Epub 2007/11/03.

17. Davies JE. Mechanisms of endosseous integration. Int J Prosthodont. 1998; 11(5):391-401. Epub 1999/01/29.

18. Romanos GE. Bone quality and the immediate loading of implants-critical aspects based on literature, research, and clinical experience. Implant Dent. 2009;18(3):203-9. Epub 2009/06/11.
19. Cawley P, Pavlakovic B, Alleyne DN, George R, Back T, Meredith N. The design of a vibration transducer to monitor the integrity of dental implants. Proc Inst Mech Eng H J Eng Med. 1998;212(4):265-72. Epub 1998/10/14.

20. Szmukler-Moncler S, Salama H, Reingewirtz Y, Dubruille JH. Timing of loading and effect of micromotion on bone-dental implant interface: review of experimental literature. J Biomed Mater Res. 1998:43(2):192-203. Epub 1998/06/10.

21. Wilmes B, Rademacher C, Olthoff G, Drescher D. Parameters affecting primary stability of orthodontic mini-implants. J Orofac Orthop. 2006;67(3): 162-74. Epub 2006/06/01.

22. Boice GW, Kraut RA. Maxillary denture retention using rare earth magnets and endosteal implants. Int J Oral Implantol. 1991;7(2):23-7. Epub 1991/01/01.

23. Sullivan DY, Sherwood RL, Collins TA, Krogh PH. The reverse-torque test: a clinical report. Int J Oral Maxillofac Implants. 1996;11(2):179-85. Epub 1996/03/01.

24. Branemark R, Ohrnell LO, Nilsson P, Thomsen P. Biomechanical characterization of osseointegration during healing: an experimental in vivo study in the rat. Biomaterials. 1997;18(14):969-78. Epub 1997/07/01.

25. Branemark R, Ohrnell LO, Skalak R, Carlsson L, Branemark PI. Biomechanical characterization of osseointegration: an experimental in vivo investigation in the beagle dog. J Orthop Res. 1998;16(1):61-9. Epub 1998/05/09.

26. Ersanli S, Karabuda C, Beck F, Leblebicioglu B. Resonance frequency analysis of one-stage dental implant stability during the osseointegration period. J Periodontol. 2005;76(7):1066-71. Epub 2005/07/16.

27. Bornstein MM, Chappuis V, von Arx T, Buser D. Performance of dental implants after staged sinus floor elevation procedures: 5-year results of a prospective study in partially edentulous patients. Clin Oral Implants Res. 2008;19(10):1034-43. Epub 2008/10/03.

28. Boronat Lopez A, Balaguer Martinez J, Lamas Pelayo J, Carrillo Garcia C, Penarrocha DM. Resonance frequency analysis of dental implant stability during the healing period. Med Oral Patol Oral Cir Bucal. 2008;13(4):E244-7. Epub 2008/04/02.

29. Quesada-Garcia MP, Prados-Sanchez E, Olmedo-Gaya MV, Munoz-Soto E, Gonzalez-Rodriguez MP, Valllecillo-Capilla M. Measurement of dental implant stability by resonance frequency analysis: a review of the literature. Med Oral Patol Oral Cir Bucal. 2009;14(10):e538-46. Epub 2009/08/15.

30. Guler AU, Duran I, Yucel AC, Ozkan P. Effects of air-polishing powders on color stability of composite resins. J Appl Oral Sci. 2011;19(5):505-10. Epub 2011/09/17.

31. Friberg B, Sennerby L, Meredith $N$, Lekholm U. A comparison between cutting torque and resonance frequency measurements of maxillary implants. A 20-month clinical study. Int J Oral Maxillofac Surg. 1999;28(4): 297-303. Epub 1999/07/23.

32. Barewal RM, Oates TW, Meredith N, Cochran DL. Resonance frequency measurement of implant stability in vivo on implants with a sandblasted and acid-etched surface. Int J Oral Maxillofac Implants. 2003;18(5):641-51. Epub 2003/10/29

33. Glauser R, Sennerby L, Meredith N, Ree A, Lundgren A, Gottlow J, et al. Resonance frequency analysis of implants subjected to immediate or early functional occlusal loading. Successful vs. failing implants. Clin Oral Implants Res. 2004;15(4):428-34. Epub 2004/07/14.

34. Sjostrom M, Lundgren S, Nilson $H$, Sennerby L. Monitoring of implant stability in grafted bone using resonance frequency analysis. A clinical study from implant placement to 6 months of loading. Int J Oral Maxillofac Surg. 2005;34(1):45-51. Epub 2004/12/25.

35. Gallucci GO, Belser UC, Bernard JP, Magne P. Modeling and characterization of the CEJ for optimization of esthetic implant design. Int J Periodontics Restorative Dent. 2004;24(1):19-29. Epub 2004/02/27.

36. Meredith N, Book K, Friberg B, Jemt T, Sennerby L. Resonance frequency measurements of implant stability in vivo. A cross-sectional and longitudinal study of resonance frequency measurements on implants in the edentulous and partially dentate maxilla. Clin Oral Implants Res. 1997;8(3):226-33. Epub 1997/06/01.

37. Meredith N, Alleyne D, Cawley P. Quantitative determination of the stability of the implant-tissue interface using resonance frequency analysis. Clin Oral Implants Res. 1996;7(3):261-7. Epub 1996/09/01.

38. Meredith N, Shagaldi F, Alleyne D, Sennerby L, Cawley P. The application of resonance frequency measurements to study the stability of titanium implants during healing in the rabbit tibia. Clin Oral Implants Res. 1997;8(3): 234-43. Epub 1997/06/01.

39. Steigenga J, Al-Shammari K, Misch C, Nociti Jr FH, Wang HL. Effects of implant thread geometry on percentage of osseointegration and resistance to reverse torque in the tibia of rabbits. J Periodontol. 2004;75(9):1233-41. Epub 2004/11/02.

40. Le Guehennec L, Goyenvalle E, Lopez-Heredia MA, Weiss P, Amouriq Y, Layrolle P. Histomorphometric analysis of the osseointegration of four 
different implant surfaces in the femoral epiphyses of rabbits. Clin Oral Implants Res. 2008;19(11):1103-10. Epub 2008/11/06.

41. Faeda RS, Tavares HS, Sartori R, Guastaldi AC, Marcantonio Jr E. Evaluation of titanium implants with surface modification by laser beam. Biomechanical study in rabbit tibias. Braz Oral Res. 2009;23(2):137-43. Epub 2009/08/18.

42. Park JW, Kim HK, Kim YJ, An CH, Hanawa T. Enhanced osteoconductivity of micro-structured titanium implants (XiVE S CELLplus) by addition of surface calcium chemistry: a histomorphometric study in the rabbit femur. Clin Oral Implants Res. 2009;20(7):684-90. Epub 2009/06/06.

43. Yang GL, He FM, Hu JA, Wang XX, Zhao SF. Effects of biomimetically and electrochemically deposited nano-hydroxyapatite coatings on osseointegration of porous titanium implants. Oral Surg Oral Med Oral Pathol Oral Radiol Endod. 2009;107(6):782-9. Epub 2009/02/10.

44. Yildiz A, Esen E, Kurkcu M, Damlar I, Daglioglu K, Akova T. Effect of zoledronic acid on osseointegration of titanium implants: an experimental study in an ovariectomized rabbit model. J Oral Maxillofac Surg. 2010;68(3): 515-23. Epub 2010/02/23.

45. Barros RR, Novaes Jr AB, Muglia VA, lezzi G, Piattelli A. Influence of interimplant distances and placement depth on peri-implant bone remodeling of adjacent and immediately loaded Morse cone connection implants: a histomorphometric study in dogs. Clin Oral Implants Res. 2010; 21(4):371-8. Epub 2010/02/05.

46. Marin C, Bonfante EA, Granato R, Suzuki M, Granjeiro JM, Coelho PG. The effect of alterations on resorbable blasting media processed implant surfaces on early bone healing: a study in rabbits. Implant Dent. 2011;20(2): 167-77. Epub 2011/03/31.

47. Green CJ, Knight J, Precious S, Simpkin S. Ketamine alone and combined with diazepam or xylazine in laboratory animals: a 10 year experience. Lab Anim. 1981;15(2):163-70. Epub 1981/04/01.

48. Chen J, Zhang Y, Rong M, Zhao L, Jiang L, Zhang D, et al. Expression and characterization of jingzhaotoxin-34, a novel neurotoxin from the venom of the tarantula Chilobrachys jingzhao. Peptides. 2009;30(6):1042-8. Epub 2009/05/26.

49. Morris HF, Ochi S, Orenstein $\mathbb{H}$, Petrazzuolo V. AICRG, Part V: factors influencing implant stability at placement and their influence on survival of Ankylos implants. J Oral Implantol. 2004;30(3):162-70. Epub 2004/07/17.

50. Manresa C, Bosch M, Echeverria JJ. The comparison between implant stability quotient and bone-implant contact revisited: an experiment in Beagle dog. Clin Oral Implants Res. 2014;25(11):1213-21. Epub 2013/10/10.

51. Alsaadi G, Quirynen M, Michiels K, Jacobs R, van Steenberghe D. A biomechanical assessment of the relation between the oral implant stability at insertion and subjective bone quality assessment. J Clin Periodontol. 2007;34(4):359-66. Epub 2007/03/24.

52. Huwiler MA, Pjetursson BE, Bosshardt DD, Salvi GE, Lang NP. Resonance frequency analysis in relation to jawbone characteristics and during early healing of implant installation. Clin Oral Implants Res. 2007;18(3):275-80. Epub 2007/03/16.

53. Zhou Y, Jiang T, Qian M, Zhang X, Wang J, Shi B, et al. Roles of bone scintigraphy and resonance frequency analysis in evaluating osseointegration of endosseous implant. Biomaterials. 2008;29(4):461-74. Epub 2007/11/07.

54. Degidi M, Perrotti V, Piattelli A, lezzi G. Mineralized bone-implant contact and implant stability quotient in 16 human implants retrieved after early healing periods: a histologic and histomorphometric evaluation. Int J Oral Maxillofac Implants. 2010;25(1):45-8. Epub 2010/03/09.

55. Dhaliwal J, Albuquerque R, Murshed, M, Tamimi, F, Feine, JS. A histomorphometric comparison of osseointegration with MDls and standard implants. IADR/AADR/ CADR 91st General Session, Seattle, Washington, USA, March 20-23, 2013

56. Zix J, Hug S, Kessler-Liechti G, Mericske-Stern R. Measurement of dental implant stability by resonance frequency analysis and damping capacity assessment: comparison of both techniques in a clinical trial. Int J Oral Maxillofac Implants. 2008;23(3):525-30. Epub 2008/08/15.

57. Roberts WE, Smith RK, Zilberman Y, Mozsary PG, Smith RS. Osseous adaptation to continuous loading of rigid endosseous implants. Am J Orthod. 1984;86(2):95-111. Epub 1984/08/01.

58. Ostman PO, Hellman M, Albrektsson T, Sennerby L. Direct loading of nobel direct and nobel perfect one-piece implants: a 1-year prospective clinical and radiographic study. Clin Oral Implants Res. 2007;18(4):409-18. Epub 2007/05/16

\section{Submit your manuscript to a SpringerOpen ${ }^{\circ}$ journal and benefit from:}

- Convenient online submission

- Rigorous peer review

- Immediate publication on acceptance

- Open access: articles freely available online

- High visibility within the field

- Retaining the copyright to your article

Submit your next manuscript at $\gg$ springeropen.com 